\title{
Inhibition of 72 kDa inositol polyphosphate 5-phosphatase E improves insulin signal transduction in diet-induced obesity
}

\author{
Daniela F Bertelli ${ }^{1}$, Andressa Coope ${ }^{1}$, Andrea M Caricilli ${ }^{2}$, Patricia O Prada ${ }^{3}$, \\ Mario J Saad ${ }^{2}$, Licio A Velloso ${ }^{1,2}$ and Eliana P Araujo ${ }^{1,4}$ \\ ${ }^{1}$ Laboratory of Cell Signaling, ${ }^{2}$ Department of Internal Medicine, ${ }^{3}$ Faculty of Applied Sciences and ${ }^{4}$ Department of \\ Nursing, University of Campinas, DCM - FCM, UNICAMP, 13084-970 - Campinas, SP, Brazil
}

\author{
Correspondence \\ should be addressed to \\ E P Araujo \\ Email \\ pa.araujo@gmail.com
}

\begin{abstract}
The 72 kDa inositol polyphosphate 5-phosphatase E (72k-5ptase) controls signal transduction through the catalytic dephosphorylation of the 5-position of membrane-bound phosphoinositides. The reduction of $72 \mathrm{k}-5$ ptase expression in the hypothalamus results in improved hypothalamic insulin signal transduction and reduction of food intake and body mass. Here, we evaluated the tissue distribution and the impact of obesity on the expression of $72 \mathrm{k}-5$ ptase in peripheral tissues of experimental animals. In addition, insulin signal transduction and action were determined in an animal model of obesity and insulin resistance treated with an antisense (AS) oligonucleotide that reduces $72 \mathrm{k}-5$ ptase expression. In lean Wistar rats, 72k-5ptase mRNA and protein are found in highest levels in heart, skeletal muscle, and white adipose tissue. In three distinct models of obesity, Wistar rats, Swiss mice fed on high-fat diet, and leptin-deficient ob/ob mice, the expression of $72 \mathrm{k}-5$ ptase is increased in skeletal muscle and adipose tissue. The treatment of obese Wistar rats with an anti-72k-5ptase AS oligonucleotide results in significant reduction of $72 \mathrm{k}-5$ ptase catalytic activity, which is accompanied by reduced food intake and body mass and improved insulin signal transduction and action as determined by immunoblotting and clamp studies respectively. $72 \mathrm{k}-5$ ptase expression is increased in obesity and its AS inhibition resulted in a significant improvement in insulin signal transduction and restoration of glucose homeostasis.
\end{abstract}
Key Words
- insulin resistance
- adipose tissue
- liver
- gluconeogenesis

\section{Introduction}

Membrane-bound phosphoinositides are molecules engaged in the transduction of signals delivered by a number of growth factors and hormones, which play a role in the control of cell growth, apoptosis, metabolism, cytoskeletal organization, and vesicular trafficking (Kutateladze 2010). The canonical phosphoinositide signaling cascade is activated by the phosphatidylinositol 3-kinase
(PI3K)-catalyzed transient phosphorylation of phosphatidylinositol 4,5-P2 (PIP2) at the $3^{\prime}$ position, producing phosphatidylinositol 3,4,5-P3 (PIP3; Engelman et al. 2006).

Due to its pleiotropic actions, the PIP3 signals are tightly controlled by either the 3-phosphoinositol phosphatase (3ptase) PTEN or a member of a group of at least ten distinct 5ptases (Blanco-Aparicio et al. 2007, 
Ooms et al. 2009). The hydrolytic removal of a phosphate group from the position-3 of PIP3 by PTEN has a significant impact on growth signals, which account for the tumor-suppressing effects of PTEN (Yin \& Shen 2008). In addition, PTEN also controls metabolic signals generated by insulin and leptin (Plum et al. 2006).

The removal of the phosphate group from position-5 of PIP3 is mostly involved in the control of calcium signaling, vesicular trafficking, and cytoskeletal organization (Ooms et al. 2009). Metabolic outcomes of this reaction were initially expected to be scarce as the activation of Akt can still take place through 3,4-P2 (PIP2) (Manning \& Cantley 2007). However, some recent studies have shown that modulation of 5 ptase activity can produce important changes in insulin and leptin signal transduction, particularly mediated by the actions of SHIP2, SKIP, and $72 \mathrm{kDa}$ inositol polyphosphate 5-phosphatase E (72k-5ptase; Ijuin et al. 2000, Clement et al. 2001, Sleeman et al. 2005, Bertelli et al. 2006, Kong et al. 2006).

Here, we evaluated the expression and outcomes of inhibiting 72k-5ptase in animal models of obesity and type 2 diabetes. As a rule, 72k-5ptase expression was increased in obese, insulin-resistant animals and the inhibition of its expression resulted in a significant improvement in insulin signal transduction and restoration of glucose homeostasis.

\section{Materials and methods}

\section{Experimental animals}

All animals used in the study were obtained from the University of Campinas Breeding Center. Most experiments were performed with 8- to 16-week, male, Wistar rats. In some experiments, we employed 16-week, male, leptin-deficient $o b / o b$ mice and their respective $\mathrm{Ob} /$ ? controls. Sixteen-week, male, Swiss mice were also used. Wistar rats and Swiss mice were randomly selected for feeding on either regular rodent chow or a high-fat (HF) diet (containing 36\% fat) for 8 weeks (composition of diet is described elsewhere (Cintra et al. 2012)). In some experiments, Wistar rats on HF diet were pair-fed with rats treated with the antisense (AS) oligonucleotide against 72k-5ptase (which reduces caloric intake). For that, mean caloric intake per gram of body mass was calculated for AS treated rats and a similar amount of diet was offered to the control rats. All experiments were approved by the University of Campinas Ethics Committee.

\section{Anesthesia and pain relief}

In all invasive experiments, mice and rats were anesthetized with a mixture of ketamine/xylazine (100/10 and 50/10 mg/kg for mice and rats respectively) injected via i.p. Pain relief was obtained by i.p. acetaminophen (100 and $50 \mathrm{mg} / \mathrm{kg}$, for mice and rats respectively).

\section{AS oligonucleotide against 72k-5ptase}

The AS oligonucleotide against 72k-5ptase was developed and employed in a previous work (Bertelli et al. 2006). Briefly, it consists of a phosphorothioate-modified 17-base sequence ( $5^{\prime}$-AGC TGT CCC TGG AGC AT-3') produced by Invitrogen-Life Technologies. A sense (S) control was also used in the study (5'-ATG CTC CAG GGA CAG CT-3'). Wistar rats were treated for 3 days (once a day, i.p.) with a $\mathrm{S}$ or an AS oligonucleotide ( $200 \mu \mathrm{l}$ containing $4 \mathrm{nmol})$. No adverse effects were observed with the use of either AS or S oligonucleotides.

\section{Antibodies, chemicals, and buffers}

Antibodies against the insulin receptor (IR; rabbit polyclonal, sc-711), IR substrate-1 (IRS1; rabbit polyclonal, sc-559), ERK1 (ERK; rabbit polyclonal, sc-94), tyrosine-204 phosphorylated ERK (pERK; mouse monoclonal, sc-7383), Akt1/2/3 (Akt; rabbit polyclonal, sc-8312), serine-473 phosphorylated Akt (pAkt; rabbit polyclonal, sc-7985R), phosphotyrosine (pTyr; mouse monoclonal, sc-508), p85 subunit of PI3K (p85; mouse monoclonal, sc-71896), p110 subunit of PI3K (p110; goat polyclonal, sc-1331), and FOXO1 (rabbit polyclonal, sc-11350) were purchased from Santa Cruz Biotechnology. Antibodies against 72k-5ptase (rabbit polyclonal, IPVS-1007) and IRS2 (rabbit polyclonal, IPVS-1002) were from Imuny (Campinas, Brazil). The anti-beta actin ( $\beta$-actin; rabbit polyclonal, ab8227) antibody was from Abcam (Cambridge, MA, USA). The antibody against serine-256 phosphorylated FOXO1 (pFOXO1; rabbit polyclonal, \#9461S) was purchased from Cell Signaling (Danvers, MA, USA). All the reagents for SDS-PAGE and immunoblotting were from Bio-Rad. HEPES, BSA (fraction V), phenylmethylsulphonyl fluoride (PMSF), aprotinin, dithiothreitol, Triton X-100, Tween 20, glycerol, collagenase, and 2-hydroxypropyl-cyclodextrin (HBP, \#01816LD) were purchased from Sigma-Aldrich. Sodium thiopental, ketamine, and diazepam were from Cristalia (Itapira, Brazil). All the chemicals and primers used in the real-time PCR experiments were purchased

Published by Bioscientifica Ltd. 
from Applied Biosystems and from Invitrogen-Life Technologies.

\section{Intraperitoneal glucose tolerance test}

The rats were submitted to an overnight fast before the test. A solution of $20 \%$ glucose $(2.0 \mathrm{~g} / \mathrm{kg}$ body mass $)$ was administered into the peritoneal cavity. Blood from the tail was collected before the glucose challenge (time 0 ), and after $5,15,30,60,90$, and $120 \mathrm{~min}$, for the determination of glucose and insulin concentrations.

\section{RNA preparation and real-time PCR}

Total RNA was extracted according to the manufacturer's recommendations using Trizol reagent (Life Technologies). Real-time PCR was performed as described previously (Coope et al. 2012). The primers used for the amplification of $72 \mathrm{k}-5$ ptase were as follows: S, 5'-CGA GGT TCT GGG TCT TCT G-3' and AS, 5'-ATT GGG GTG CTG ACT TTG A-3', obtained from Applied Biosystems. Glyceraldehyde-3-phosphate dehydrogenase (GAPDH, \#4352338E) (Applied Biosystems) was used as control. Gene expression analysis was performed in an ABI Prism 7500 sequence detection system (Applied Biosystems).

\section{Tissue extraction, immunoprecipitation, and immunoblotting}

After specific treatments, the rats and/or mice were anesthetized and tissue samples were obtained and homogenized in a freshly prepared solubilization buffer (1\% Triton X-100, $100 \mathrm{mM}$ Tris, $\mathrm{pH}$ 7.4, $100 \mathrm{mM}$ sodium pyrophosphate, $100 \mathrm{mM}$ sodium fluoride, $10 \mathrm{mM}$ EDTA, $10 \mathrm{mM}$ sodium vanadate, $2 \mathrm{mM} \mathrm{PMSF}$, and $0.01 \mathrm{mg}$ aprotinin $/ \mathrm{ml}$ ] for evaluation of protein expression. The insoluble material was removed by centrifugation $(10000 \mathrm{~g})$ for $30 \mathrm{~min}$ at $4{ }^{\circ} \mathrm{C}$. The protein concentration of the supernatants was determined by the Bradford dye binding method. Aliquots of the supernatants containing $1.0 \mathrm{mg}$ total protein were used for immunoprecipitation with specific antibodies against $72 \mathrm{k}-5$ ptase, -IR, -IRS1, or -IRS2 at $4{ }^{\circ} \mathrm{C}$, overnight, followed by the addition of protein A-Sepharose $6 \mathrm{MB}$ (Pharmacia) for $2 \mathrm{~h}$ and centrifuged at $10000 \boldsymbol{g}$ for $15 \mathrm{~min}$ at $4{ }^{\circ} \mathrm{C}$. The pellets were washed three times in ice-cold buffer $(0.5 \%$ Triton $\mathrm{X}-100,100 \mathrm{mM}$ Tris, $\mathrm{pH}$ 7.4, $10 \mathrm{mM}$ EDTA, and $2 \mathrm{mM}$ sodium vanadate), resuspended in Laemmli sample buffer, and boiled for $5 \mathrm{~min}$, followed by SDS-PAGE transfer to nitrocellulose membranes. The nitrocellulose transfers
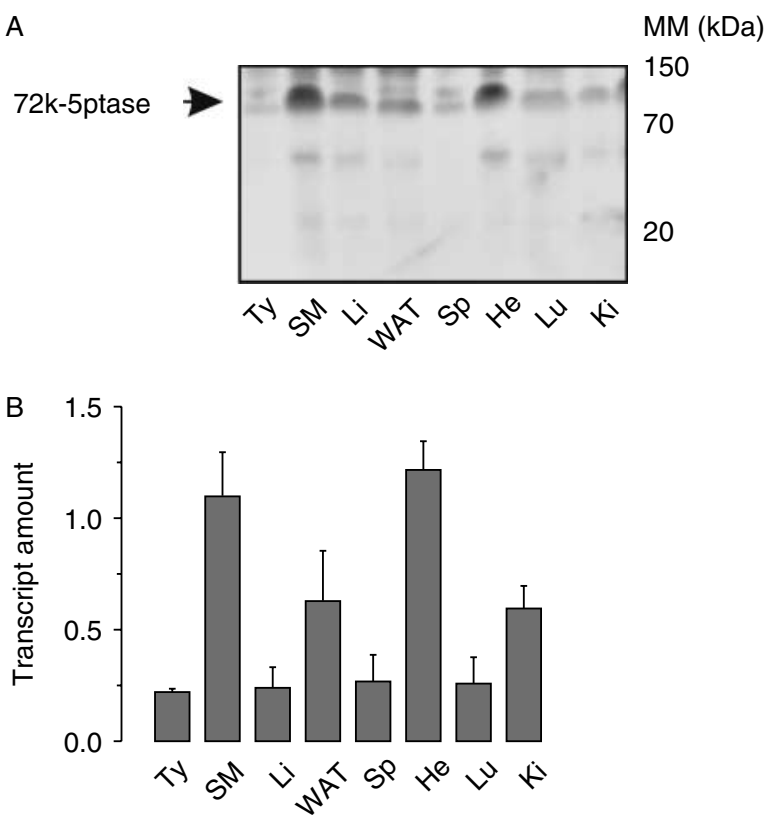

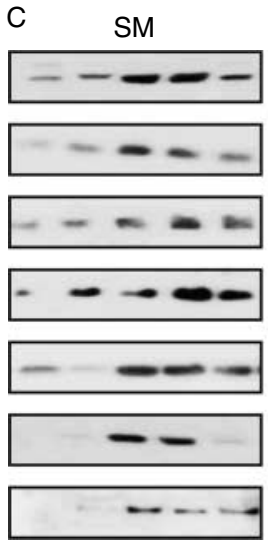

$\begin{array}{lllll}0 & 5 & 10 & 15 & 20\end{array}$

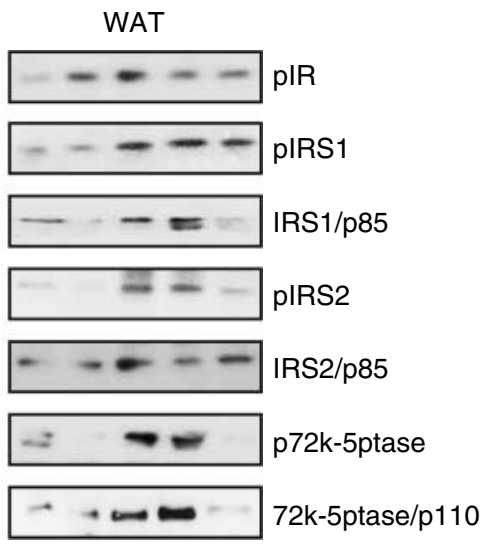

$\begin{array}{llllll}0 & 5 & 10 & 15 & 20 & \text { Insulin (time, } \mathrm{min} \text { ) }\end{array}$

Figure 1

Tissue expression and insulin-induced phosphorylation of 72k-5ptase. One hundred and fifty micrograms of total protein extracts, obtained from thymus (Ty), skeletal muscle (SM), liver (Li), white adipose tissue (WAT), spleen ( $\mathrm{Sp}$ ), cardiac muscle ( $\mathrm{He}$ ), lung ( $\mathrm{Lu})$, and kidney (Ki), from 8-week old male Wistar rats were separated by SDS-PAGE, transferred to nitrocellulose membranes and blotted with anti-72k-5ptase antibody. The specific bands are indicated by the arrow in the left-hand margin of the panel (A). Total RNA obtained from Ty, SM, Li, WAT, Sp, He, Lu, and Ki from 8-week old male Wistar rats were reverse transcribed into CDNA and employed in real-time PCRs to determine the transcript amount of the $72 \mathrm{k}$-5ptase (B). In C, 8-week old male Wistar rats were anesthetized and acutely treated with a single i.v. dose of insulin $\left(200 \mu \mathrm{l}, 10^{-6} \mathrm{M}\right)$. Specimens of SM and WAT were obtained at different times after insulin injection, as depicted in the panels. Tyrosine phosphorylation of the insulin receptor ( $p I R)$, insulin receptor substrates 1 and 2 (pIRS1/pIRS2) and 72k-5ptase (p72k-5ptase), and the associations of IRS1/IRS2 with the p85 subunit of PI3K and 72k-5ptase with the $\mathrm{p} 110$ subunit of PI3K were evaluated by immunoprecipitation and/or immunoblotting. In all experiments, $n=5$.

Published by Bioscientifica Ltd 
were probed with anti-phosphotyrosine, -72k-5ptase, -IR, -IRS-1, -IRS-2, -p85/PI3K, or -p110/PI3K. For direct immunoblot analysis, 0.05-0.2 $\mathrm{mg}$ protein from tissue extracts was separated by SDS-PAGE, transferred to nitrocellulose membranes, and blotted with anti-ERK, -pERK, -FOXO1, -pFOXO1, -Akt, -pAkt, -IRS1, -72k-5ptase, or - $\beta$ actin. Specific bands were detected by chemiluminescence.

\section{PI4,5-P2 5-phosphatase assay}

For determination of the catalytic activity of $72 \mathrm{k}-5$ ptase, we used a previously described method (Bertelli et al. 2006). In short, $72 \mathrm{k}-5$ ptase was immunoprecipitated from samples (2.0 $\mathrm{mg}$ total protein) of skeletal muscle and adipose tissue. Protein A-Sepharose pellets were resuspended in a $50 \mu \mathrm{l}$ solution containing $20 \mathrm{~mm}$ Tris (pH 7.2), $150 \mathrm{~mm} \mathrm{NaCl}, 200 \mu \mathrm{g} / \mathrm{ml} \mathrm{BSA}, 3.0 \mathrm{~mm} \mathrm{MgCl}_{2}$, $2.0 \mathrm{~mm}$ cetyltrimethylammonium bromide, and $250 \mathrm{~mm}$ [3H]PI4,5-P2 (3500 c.p.m./nmol). Reactions were performed for $30 \mathrm{~min}$ at $37^{\circ} \mathrm{C}$. Products were separated by TLC in chloroform/methanol/acetic acid/ $\mathrm{H}_{2} \mathrm{O}$ (43:38:4:7). Lipids were visualized on TLC plates by iodine staining and compared with the migration of known standards PI, PI4-P1, and PI4,5-P2. Products of the reaction were excised from the TLC plate and quantified by liquid scintillation counting. Protein samples treated with no $72 \mathrm{k}-5$ ptase antibody, but only with protein A-Sepharose, were used as a control.

\section{Hyperinsulinemic-euglycemic clamp}

After a 12-h fast, the rats were anesthetized with sodium pentobarbital $(50 \mathrm{mg} / \mathrm{kg}$ body weight) i.p. and catheters were placed into the left jugular vein and carotid artery. A prime continuous insulin infusion at a rate of $3.6 \mathrm{mU} / \mathrm{kg}$ body weight per minute was performed to increase the plasma insulin concentration to $\sim 800-900 \mathrm{pmol} / \mathrm{l}$. Blood samples $(20 \mu \mathrm{l})$ were collected at 5 -min intervals for measurement of plasma glucose concentration and $10 \%$ glucose was infused at variable rates to maintain plasma glucose at fasting levels. All infusions were performed using Harvard infusion pumps.

\section{Statistical analysis}

Specific protein bands present in the blots were quantified by digital densitometry (UN-SCAN-IT). The numerical results, expressed as mean values and \pm s.E.M. obtained from real-time PCR, densitometry scans, body mass determination, and food intake were compared using
Tukey-Kramer test (ANOVA) or Student's $t$-test, as appropriate. A $P<0.05$ was accepted as statistically significant. In all experiments, $n$ refers to the number of animals in each experimental group.

\section{Results}

\section{2k-5ptase is highly expressed in muscle (skeletal and cardiac) and white adipose tissue of rats}

The expression of the enzyme $72 \mathrm{k}-5$ ptase was evaluated by immunoblot (Fig. 1A) and real-time PCR (Fig. 1B) in several tissues obtained from 8-week old male Wistar rats. As depicted in the figures, protein and mRNA expression of $72 \mathrm{k}-5$ ptase could be detected in most tissues evaluated. However, the highest levels of 72k-5ptase were detected in skeletal and cardiac muscle and in white adipose tissue.

\section{Insulin induces the tyrosine phosphorylation of 72k-5ptase}

Following an i.v. bolus injection of insulin, skeletal muscle and white adipose tissue samples were collected and employed in immunoprecipitation and immunoblotting experiments to evaluate the activation of signal

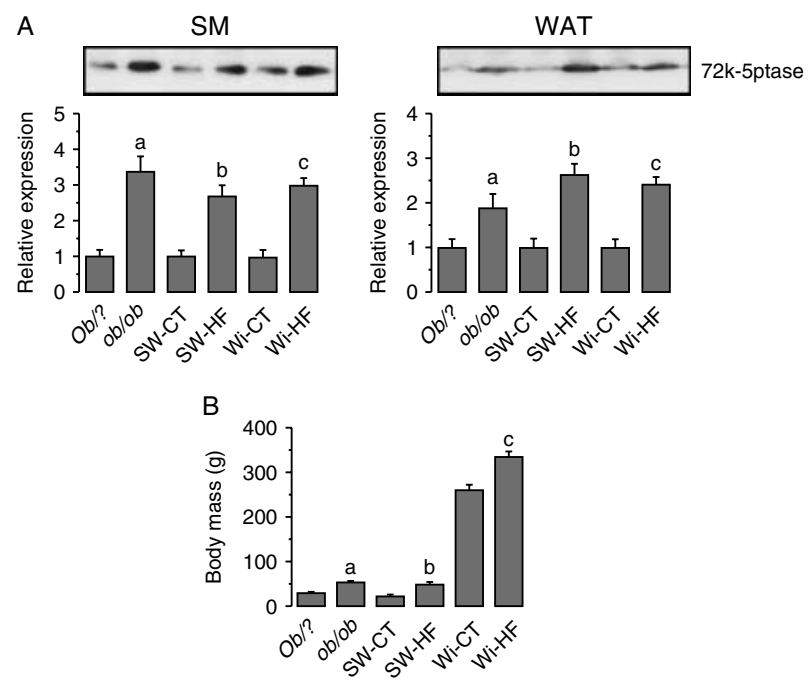

Figure 2

Expression of 72k-5ptase in experimental models of obesity. The expression of 72k-5ptase was evaluated by immunoblot in skeletal muscle (SM) and white adipose tissue (WAT) of 16-week lean (Ob/?) and obese ob/ob mice and in either Swiss mice (SW) or Wistar rats (Wi) fed on regular chow (CT) or a high-fat diet (HF) for 8 weeks (A). B depicts the body mass of the experimental animals employed in $A$ at the time of tissue collection. In all experiments, $n=5$. In $\mathrm{A}$ and $\mathrm{B}$, letters $\mathrm{a}, \mathrm{b}$ and $\mathrm{c}$ represent $P<0.05$ vs respective lean control.

Published by Bioscientifica Ltd. 
transduction through the IR/IRS/PI3K pathway. As shown in Fig. 1C, insulin induced the tyrosine phosphorylation of $72 \mathrm{k}-5$ ptase, both in skeletal muscle and in adipose tissue, beginning at $10 \mathrm{~min}$ after insulin injection and returning to the steady-state dephosphorylated condition at $20 \mathrm{~min}$. This time course was similar to the insulininduced activation of the proteins of the canonical signaling pathway, such as IR, IRS1, and IRS2. In addition, the insulin-induced tyrosine phosphorylation of $72 \mathrm{k}-5$ ptase was accompanied by its increased association with the p110 subunit of PI3K.

\section{2k-5ptase expression is increased in obesity}

The expression of $72 \mathrm{k}-5$ ptase was evaluated in skeletal muscle and adipose tissue of three distinct models of obesity, the leptin-deficient, obesity- and diabetes-prone $o b / o b$ mouse, the obesity- and diabetes-prone Swiss mouse, and the obesity-prone, diabetes-protected Wistar rat. Samples were always collected from 16-week-old rats/mice. The $o b / o b$ and $O b / ?$ mice were fed on regular chow. Swiss mice and Wistar rats were fed for 8 weeks (beginning at 8 weeks of age) on either chow (CT) or HF diet. In $o b / o b$ mice and either in Swiss or Wistar fed on HF diet, the expression of 72k-5ptase was increased by at least twofold (Fig. 2A), as compared with their respective lean controls. The body mass of the experimental models is depicted in Fig. 2B.

\section{The expression and activity of 72k-5ptase can be reduced by an AS oligonucleotide}

The short-term treatment of Wistar rats with an anti72k-5ptase AS oligonucleotide reduced skeletal muscle and adipose tissue expression of 72k-5ptase (Fig. 3A) and inhibited insulin-induced activation of the catalytic activity of the enzyme (Fig. 3B).

\section{Inhibition of 72k-5ptase expression reduces food intake and body mass}

Daily treatment for 7 days with the anti-72k-5ptase AS oligonucleotide produced significant reductions in spontaneous daily food intake (Fig. 4A) and cumulative intake during the treatment period (Fig. 4B). The decrease in food intake resulted in a reduction in body mass gain (Fig. 4C and D). Both the reduction in food intake and body mass gain were promptly restored after the interruption of the AS treatment (Fig. 4A and C).
The inhibition of 72k-5ptase expression partially corrects defective glucose-stimulated insulin secretion in obese rats

In Wistar rats, diet-induced obesity results in insulin resistance without affecting glucose homeostasis, due to the intrinsic capacity of the pancreatic islet to compensate for peripheral needs (Calegari et al. 2011). Upon 72k-5ptase inhibition, no modification of the glucose curve during the glucose tolerance test was detected (Fig. 4E). Nevertheless, insulin secretion was markedly
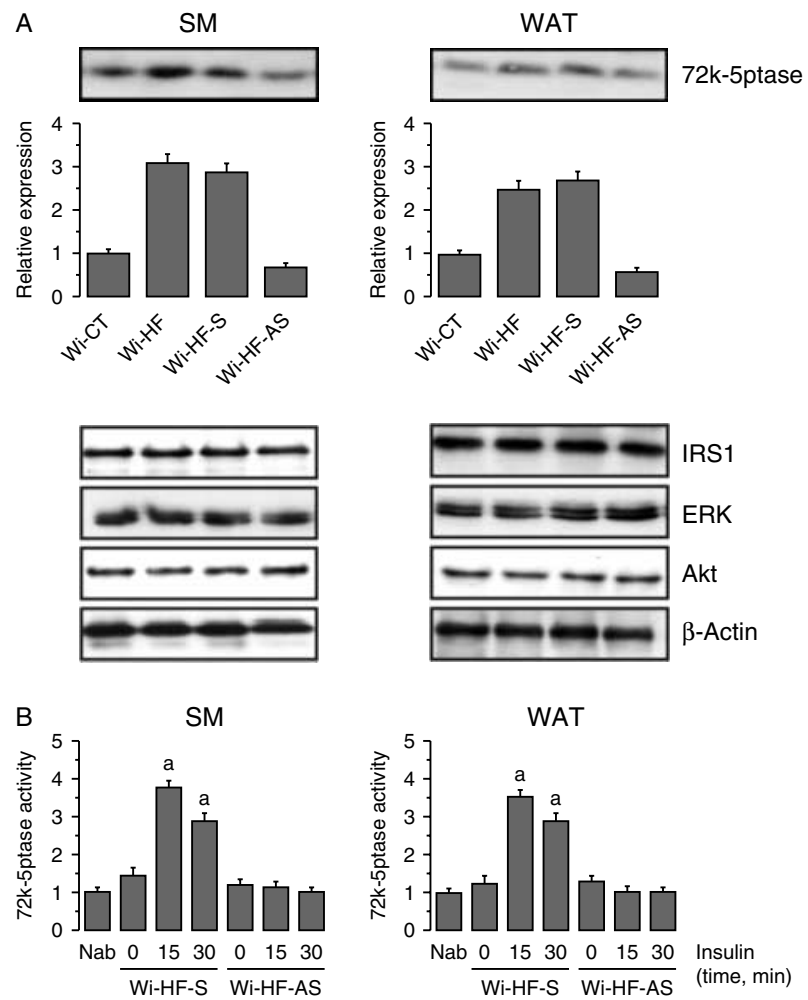

Figure 3

Inhibition of 72k-5ptase with AS oligonucleotide. The expressions of 72k-5ptase, IRS1, ERK, Akt, and $\beta$-actin were evaluated by immunoblot in the skeletal muscle (SM) and white adipose tissue (WAT) of lean (CT) and obese (HF) Wistar rats (Wi) treated for 3 days (once a day, i.p.) with saline $(200 \mu \mathrm{l})(\mathrm{Wi}-\mathrm{CT}, \mathrm{Wi}-\mathrm{HF})$ or with a sense (S) or an AS oligonucleotide (200 $\mu$ l containing $4 \mathrm{nmol}$ ) against $72 \mathrm{k}-5$ ptase (A). The activity of 72k-5ptase was evaluated in 72k-5ptase immunoprecipitates collected from the SM and WAT of obese (HF) Wistar rats treated for 3 days (once a day, i.p.) with a $S$ or an AS oligonucleotide (200 $\mu \mathrm{l}$ containing $4 \mathrm{nmol}$ ) against $72 \mathrm{k}-5$ ptase (B).

Rats were anesthetized and acutely treated with a single i.v. dose of insulin $\left(200 \mu \mathrm{l}, 10^{-6} \mathrm{M}\right)$. Specimens were obtained at different times after insulin injection, as depicted in the panels. Samples of total protein extracts not submitted to immunoprecipitation with anti-72k-5ptase ( $\mathrm{Nab}$ ) are used to normalize the activity of the enzyme. In all experiments, $n=5 . \ln \mathrm{B}$, a represents $P<0.05$ vs Wi-HF-S at time 0 min.

Published by Bioscientifica Ltd. 
reduced during the test (Fig. $4 \mathrm{~F}$ and $\mathrm{G}$ ), suggesting that the reduction in $72 \mathrm{k}-5$ ptase activity could contribute to improved insulin action. It is noteworthy that the reduction in insulin secretion was not due to the anorexigenic effect of the AS oligonucleotide approach, as pair-fed rats retained the defect of insulin secretion as observed in obese rats (Fig. 4F and G).
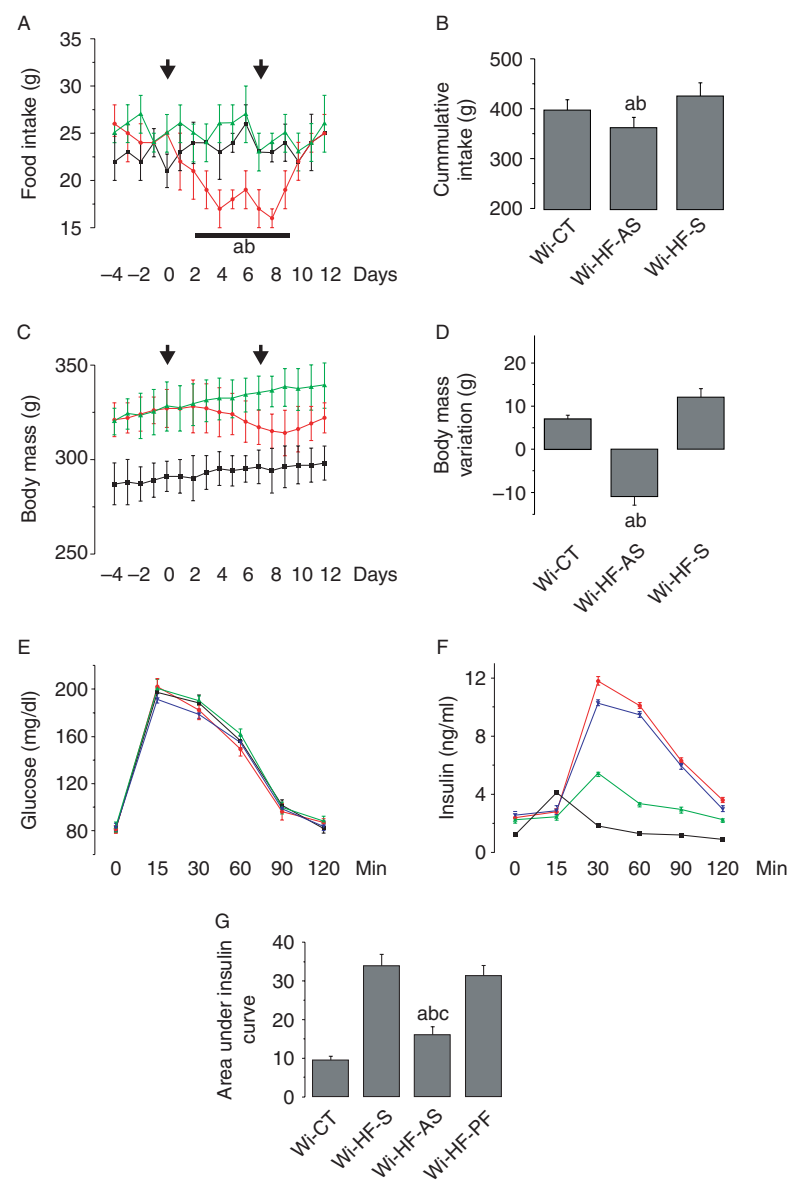

\section{Figure 4}

Food intake, body mass, and glucose homeostasis during 72k-5ptase inhibition. Male Wistar rats fed on regular chow (CT) or a high-fat diet (HF) for 8 weeks were treated once a day with an i.p. injection of saline $(200 \mu \mathrm{l})$ (Wi-CT, black), sense (Wi-HF-S, green), or AS (Wi-HF-AS, red) anti-72k-5ptase oligonucleotide for 7 days (depicted by the arrows in A and C). Daily food intake (A) and cumulative food intake between the first and last days of treatment (B) were recorded, as well as the daily body mass (C) and body mass variation (D) during the same periods. Serum glucose $(E)$ and insulin $(F)$ levels were determined during an intraperitoneal glucose tolerance test performed on the sixth day of treatment. In $E$ and $F$, a group of Wistar rats fed on HF diet and pair-fed (Wi-HF-PF, blue) with the Wi-HF-AS group was included. The areas under the insulin curves were calculated $(G)$. In all experiments, $n=5$. In $\mathrm{B}, \mathrm{D}$, and $\mathrm{G}$, a represents $P<0.05 \mathrm{vs} \mathrm{Wi}-\mathrm{CT}$, b represents $P<0.05$ vs Wi-HF-S and c represents $P<0.05$ vs Wi-HF-PF. Full colour version of this figure available via http://dx.doi.org/10.1530/JOE-12-0562.

\section{Correction of diet-induced insulin resistance by the inhibition of 72k-5ptase expression}

The action of insulin was evaluated by the euglycemichyperinsulinemic clamp method. As shown in Fig. 5A, the inhibition of $72 \mathrm{k}-5$ ptase completely corrected dietinduced insulin resistance as measured by the glucose infusion rate during the clamp. This effect was accompanied by increased insulin-stimulated activation of Akt and FOXO1, but not of ERK, in both the skeletal muscle (Fig. 5B) and the adipose tissue (Fig. 5C) of obese rats.

\section{Discussion}

PI3K activation is one of the most important events in insulin signal transduction (Folli et al. 1993, Engelman et al. 2006, Taniguchi et al. 2006). Following an insulin stimulus, the IRS proteins are tyrosine phosphorylated and interact with the p85 subunit of PI3K, leading to its activation and targeting to the plasma membrane (Folli et al. 1992, Virkamaki et al. 1999). The enzyme generates the membrane-bound lipid product, PIP3, which regulates the localization and activity of a number of proteins that are important for transducing the insulin signal (Engelman et al. 2006, Taniguchi et al. 2006, Kizelsztein et al. 2009, Esposito et al. 2012). PI3K plays a critical role in Glut4 translocation and glucose uptake. The pharmacological inhibition of the enzyme completely blocks the stimulation of glucose uptake by insulin (Martin et al. 1996). In addition, while the expression of a dominantnegative form of PI3K can reduce glucose uptake and Glut4 translocation, the overexpression of a constitutively active form of the enzyme can mimic insulin action (Quon et al. 1995, Ueki et al. 2002).

Due to its important role in a number of different cellular events, which can be activated not only by insulin but also by an array of hormones, growth factors, and cytokines, the PI3K signaling system is regarded as an attractive potential target for drug therapy of a number of diseases. While reducing its activity can be important for the control of cell-proliferative disorders (Courtney et al. 2010), the stimulation of the PI3K signaling activity, either by increasing its catalytic activity, or by reducing the activity of the inositol phosphatases, may be beneficial in diabetes and obesity (Lazar \& Saltiel 2006).

A number of recent studies have evaluated the impact of targeting the 5 ptases on energy and glucose homeostasis. The inhibition of at least three (SHIP2, SKIP, and 72k-5ptase) out of ten known 5ptases has shown

Published by Bioscientifica Ltd. 
promising results in the regulation of metabolic events (Ooms et al. 2009). SHIP2, which is expressed in cells of the hematopoietic system and a number of other tissues, such as the brain, skeletal muscle, heart, liver, and kidney, was the first to be identified as a potential therapeutic target in obesity and diabetes (Pesesse et al. 1997, Muraille et al. 1999). In distinct cultured cell types, the overexpression of
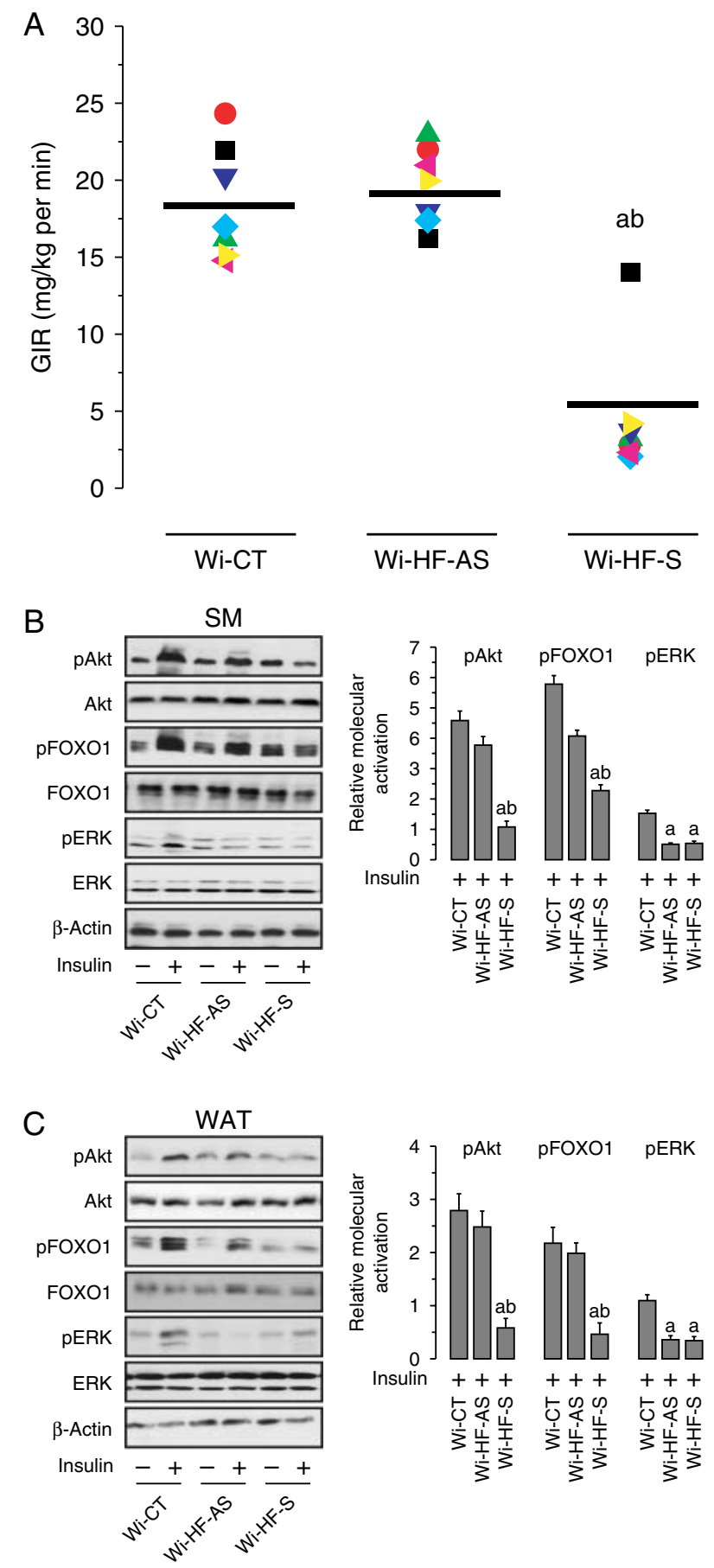

http://joe.endocrinology-journals.org DOI: 10.1530/JOE-12-0562
SHIP2 reduces insulin signal transduction and glucose uptake (Sasaoka et al. 2001, Wada et al. 2001). The knockout of the ship2 gene, which has been carried out by different groups, resulted in variable degrees of increased insulin sensitivity, which were, apparently, due to the distinct genetic approaches used to target the gene (Clement et al. 2001, Bertelli et al. 2006). Additional proof of the role of SHIP2 in insulin signaling was obtained by reducing the protein expression by an AS oligonucleotide (Bertelli et al. 2003).

SKIP, a $51 \mathrm{kDa}$ protein expressed predominantly in the heart, skeletal muscle, and kidney, is apparently more involved in the hydrolysis of PIP2 than of PIP3 (Ijuin et al. 2000, Ijuin \& Takenawa 2003). Nevertheless, its overexpression in an isolated cell system leads to reduced insulin-induced Akt activation and Glut4 translocation (Ijuin \& Takenawa 2003). Conversely, SKIP knockdown using AS oligonucleotides or siRNA results in increased insulin-induced Akt activation (Ijuin \& Takenawa 2003).

The 72k-5ptase, also known as INPP5E, is expressed in a number of tissues of humans and rodents (Kisseleva et al. 2000, Kong et al. 2000). It is a cytosolic protein with predominant perinuclear and Golgi localization that hydrolyses the 5-position phosphate from PIP2 and PIP3 (Kong et al. 2000). The 72k-5ptase is reported to be the most potent of the 5 ptases on the basis of kinetic analysis (Kisseleva et al. 2000, Kong et al. 2000). The overexpression of $72 \mathrm{k}-5$ ptase in cultured adipocytes results in the increased translocation of Glut 4 to the cell membrane (Kong et al. 2006). However, as this result is based on ectopic expression of the 5 ptase, it does not provide absolute evidence that 72k-5ptase plays a physiological role in the regulation of Glut4 translocation in vivo (Kong et al. 2006). In a living organism, we were able to knockdown the expression of the 72k-5ptase in the hypothalamus, which resulted in increased hypothalamic

\section{Figure 5}

Inhibition of 72k-5ptase improves the action of insulin in obesity. Male Wistar rats, fed on regular chow (CT) or a high-fat diet (HF) for 8 weeks, were treated once a day with an i.p. injection of saline $(200 \mathrm{ml})(\mathrm{Wi}-\mathrm{CT})$, sense (Wi-HF-S), or antisense (Wi-HF-AS) anti-72k-5ptase oligonucleotide for 7 days. The glucose infusion rate (GIR) was determined during a hyperinsulinemic-euglycemic clamp (A). Insulin signal transduction was evaluated in the skeletal muscle (SM) (B) and white adipose tissue (WAT) (C) by the determination of basal $(-)$ and insulin-induced $(+)$ serine phosphorylation of Akt (pAkt), threonine phosphorylation of FOXO1 (pFOXO1), and tyrosine phosphorylation of ERK (pERK). Protein loading was evaluated by re-probing the membranes with anti- $\beta$-actin antibody. In all experiments, $n=5$. In all, a represents $P<0.05$ vs Wi-CT; b represents $P<0.05$ vs Wi-HF-AS. Full colour version of this figure available via http://dx. doi.org/10.1530/JOE-12-0562.

Published by Bioscientifica Ltd 
responsiveness to insulin, reduced food intake, and reduced body mass (Bertelli et al. 2006).

Considering the apparently high catalytic activity of the $72 \mathrm{k}-5$ ptase and its ubiquitous expression in the body, we decided to employ the same AS oligonucleotide employed in the hypothalamus (Bertelli et al. 2006) to study the metabolic effects of whole-body knockdown of this 5 ptase in rodents. The distribution of the $72 \mathrm{k}-5$ ptase in different tissues of the body has been evaluated in at least two previous studies (Kisseleva et al. 2000, Kong et al. 2000), which showed high expression in the brain, heart, skeletal muscle, kidney, pancreas, and testis. Here, we expanded these studies showing that, in addition to most of the previously reported sites of high 72k-5ptase expression, the white adipose tissue also expresses this enzyme in levels similar to those seen in the kidney.

As the skeletal muscle and the white adipose tissue are the most important targets for insulin action for the control of glucose uptake, we focused the remainder of the experiments in these two tissues. As previously shown in the hypothalamus (Bertelli et al. 2006), in both skeletal muscle and in white adipose tissue, insulin is capable of acutely inducing the tyrosine phosphorylation of $72 \mathrm{k}-5$ ptase. This is rapidly followed by its binding to the p110 subunit of PI3K. It is believed that the tyrosine phosphorylation and targeting to PI3K is important for the catalytic activation and subcellular localization of 72k-5ptase (Bertelli et al. 2006), although this is yet to be confirmed. As in the hypothalamus (Bertelli et al. 2006), the use of an AS oligonucleotide targeting 72k-5ptase was capable of significantly reducing the expression of the enzyme in skeletal muscle and white adipose tissue. The reduction in the amount of $72 \mathrm{k}-5$ ptase protein was followed by a reduction in the catalytic activity of the enzyme.

Next, we evaluated the expression of $72 \mathrm{k}-5$ ptase in three distinct animal models of obesity. We selected two models of obesity induced by HF diet and a genetic model lacking leptin, the $o b / o b$ mouse. In all three models, the expression of $72 \mathrm{k}-5$ ptase was significantly increased in both skeletal muscle and white adipose tissue. Interestingly, a number of studies have shown that PTP1B, a tyrosine phosphatase known to exert an important regulatory role in insulin and leptin signaling, is increased in obesity, and this increased expression is thought to be one of the main mechanisms connecting increased adiposity to insulin and leptin resistance (Bence et al. 2006, Picardi et al. 2008). Thus, we suspect that the increased expression of $72 \mathrm{k}-5$ ptase in obesity is yet another mechanism promoting resistance to insulin and leptin.
The potential role of the increased expression of $72 \mathrm{k}-5$ ptase in obesity-associated insulin resistance was further evidenced by the fact that knocking down the expression of the enzyme in obese rats was sufficient for improving glucose homeostasis, as measured by the GTT and the clamp, and also for improving insulin signal transduction in both muscle and fat. All these effects were independent of the reduction in food intake, as they were maintained when compared with obese pair-fed rats. At this point, we cannot exclude the potential role of reducing brain expression of $72 \mathrm{k}-5$ ptase as a mechanism involved in the systemic metabolic outcomes reported herein; however, as one of the main consequences of the hypothalamic activity of $72 \mathrm{k}-5$ ptase is the control of food intake, the pair-feeding experiments provide an important control. Importantly, knocking down $72 \mathrm{k}-5$ ptase produced no changes in the expressions of a number of proteins of the insulin signal transduction pathway (Taniguchi et al. 2006). In addition, the reduction of 72k-5ptase expression did not affect fasting glucose levels, which is an important fact considering the potentiality of this enzyme as a target for the treatment of diabetes. Although we have not focused herein on this question, the low levels of $72 \mathrm{k}-5$ ptase expression in the liver may account, at least in part, for this outcome. It is possible that other 5ptases, such as SHIP2, SKIP, or synaptojanins (McPherson et al. 1996, Ijuin et al. 2000, Ooms et al. 2009), play a role in the control of the hepatic activity of insulin.

The evaluation of important steps of insulin signal transduction in muscle and adipose tissue revealed that knocking down 72k-5ptase improved signaling through Akt and FOXO1, only, but not through ERK. As insulininduced ERK activation occurs predominantly through the Shc/Grb pathway (Chen et al. 1995), and is mostly related to the control of cell growth (Boulton et al. 1991), we believe this provides evidence for the pathway specificity of the AS approach and shows that the beneficial effect of reducing the expression of 72k-5ptase in obesity is potentially due to its action in improving PI3K/Akt signal transduction.

This study provides further advance in the understanding of the complex and redundant mechanisms that control metabolic signal transduced through the PI3K system. In addition, we place $72 \mathrm{k}-5$ ptase as a potential target for the treatment of diabetes and obesity, showing that, in addition to the previously reported effect on food intake, reducing the activity of this enzyme can act directly by enhancing insulin signal transduction in peripheral tissues.

Published by Bioscientifica Ltd. 


\section{Declaration of interest}

The authors declare that there is no conflict of interest that could be perceived as prejudicing the impartiality of the research reported.

\section{Funding}

Grants for this study were provided by Fundação de Amparo à Pesquisa do Estado de São Paulo. The Laboratory of Cell Signaling belongs to the National Institute of Science and Technology for the Study of Diabetes and Obesity.

\section{Acknowledgements}

The authors thank $\mathrm{Dr} \mathrm{N}$ Conran, from the University of Campinas, for editing the English grammar and Mr G Ferraz and Mr M Cruz for technical assistance.

\section{References}

Bence KK, Delibegovic M, Xue B, Gorgun CZ, Hotamisligil GS, Neel BG \& Kahn BB 2006 Neuronal PTP1B regulates body weight, adiposity and leptin action. Nature Medicine 12 917-924. (doi:10.1038/nm1435)

Bertelli DF, Ueno M, Amaral ME, Toyama MH, Carneiro EM, Marangoni S, Carvalho CR, Saad MJ, Velloso LA \& Boschero AC 2003 Reversal of denervation-induced insulin resistance by SHIP2 protein synthesis blockade. American Journal of Physiology. Endocrinology and Metabolism 284 E679-E687.

Bertelli DF, Araujo EP, Cesquini M, Stoppa GR, Gasparotto-Contessotto M, Toyama MH, Felix JV, Carvalheira JB, Michelini LC, Chiavegatto S et al. 2006 Phosphoinositide-specific inositol polyphosphate 5-phosphatase IV inhibits inositide trisphosphate accumulation in hypothalamus and regulates food intake and body weight. Endocrinology 147 5385-5399. (doi:10.1210/en.2006-0280)

Blanco-Aparicio C, Renner O, Leal JF \& Carnero A 2007 PTEN, more than the AKT pathway. Carcinogenesis 28 1379-1386. (doi:10.1093/carcin/ bgm052)

Boulton TG, Nye SH, Robbins DJ, Ip NY, Radziejewska E, Morgenbesser SD, DePinho RA, Panayotatos N, Cobb MH \& Yancopoulos GD 1991 ERKs: a family of protein-serine/threonine kinases that are activated and tyrosine phosphorylated in response to insulin and NGF. Cell 65 663-675. (doi:10.1016/0092-8674(91)90098-J)

Calegari VC, Torsoni AS, Vanzela EC, Araujo EP, Morari J, Zoppi CC, Sbragia L, Boschero AC \& Velloso LA 2011 Inflammation of the hypothalamus leads to defective pancreatic islet function. Journal of Biological Chemistry $\mathbf{2 8 6}$ 12870-12880. (doi:10.1074/jbc.M110.173021)

Chen D, Van Horn DJ, White MF \& Backer JM 1995 Insulin receptor substrate 1 rescues insulin action in CHO cells expressing mutant insulin receptors that lack a juxtamembrane NPXY motif. Molecular and Cellular Biology 15 4711-4717.

Cintra DE, Ropelle ER, Moraes JC, Pauli JR, Morari J, Souza CT, Grimaldi R, Stahl M, Carvalheira JB, Saad MJ et al. 2012 Unsaturated fatty acids revert diet-induced hypothalamic inflammation in obesity. PLOS ONE 7 e30571. (doi:10.1371/journal.pone.0030571)

Clement S, Krause U, Desmedt F, Tanti JF, Behrends J, Pesesse X, Sasaki T, Penninger J, Doherty M, Malaisse W et al. 2001 The lipid phosphatase SHIP2 controls insulin sensitivity. Nature 409 92-97. (doi:10.1038/ 35051094)

Coope A, Milanski M, Arruda AP, Ignacio-Souza LM, Saad MJ, Anhe GF \& Velloso LA 2012 Chaperone insufficiency links TLR4 protein signaling to endoplasmic reticulum stress. Journal of Biological Chemistry $\mathbf{2 8 7}$ 15580-15589. (doi:10.1074/jbc.M111.315218)
Courtney KD, Corcoran RB \& Engelman JA 2010 The PI3K pathway as drug target in human cancer. Journal of Clinical Oncology 28 1075-1083. (doi:10.1200/JCO.2009.25.3641)

Engelman JA, Luo J \& Cantley LC 2006 The evolution of phosphatidylinositol 3-kinases as regulators of growth and metabolism. Nature Reviews. Genetics 7 606-619. (doi:10.1038/nrg1879)

Esposito D, Kizelsztein P, Komarnytsky S \& Raskin I 2012 Hypoglycemic effects of brassinosteroid in diet-induced obese mice. American Journal of Physiology. Endocrinology and Metabolism 303 E652-E658. (doi:10.1152/ajpendo.00024.2012)

Folli F, Saad MJ, Backer JM \& Kahn CR 1992 Insulin stimulation of phosphatidylinositol 3-kinase activity and association with insulin receptor substrate 1 in liver and muscle of the intact rat. Journal of Biological Chemistry 267 22171-22177.

Folli F, Saad MJ, Backer JM \& Kahn CR 1993 Regulation of phosphatidylinositol 3-kinase activity in liver and muscle of animal models of insulin-resistant and insulin-deficient diabetes mellitus. Journal of Clinical Investigation 92 1787-1794. (doi:10.1172/JCI116768)

Ijuin T \& Takenawa T 2003 SKIP negatively regulates insulin-induced GLUT4 translocation and membrane ruffle formation. Molecular and Cellular Biology 23 1209-1220. (doi:10.1128/MCB.23.4.12091220.2003)

Ijuin T, Mochizuki Y, Fukami K, Funaki M, Asano T \& Takenawa T 2000 Identification and characterization of a novel inositol polyphosphate 5-phosphatase. Journal of Biological Chemistry 275 10870-10875. (doi:10.1074/jbc.275.15.10870)

Kisseleva MV, Wilson MP \& Majerus PW 2000 The isolation and characterization of a cDNA encoding phospholipid-specific inositol polyphosphate 5-phosphatase. Journal of Biological Chemistry 275 20110-20116. (doi:10.1074/jbc.M910119199)

Kizelsztein P, Govorko D, Komarnytsky S, Evans A, Wang Z, Cefalu WT \& Raskin I 2009 20-Hydroxyecdysone decreases weight and hyperglycemia in a diet-induced obesity mice model. American Journal of Physiology. Endocrinology and Metabolism 296 E433-E439. (doi:10.1152/ ajpendo.90772.2008)

Kong AM, Speed CJ, O'Malley CJ, Layton MJ, Meehan T, Loveland KL, Cheema S, Ooms LM \& Mitchell CA 2000 Cloning and characterization of a 72-kDa inositol-polyphosphate 5-phosphatase localized to the Golgi network. Journal of Biological Chemistry 275 24052-24064. (doi:10.1074/jbc.M000874200)

Kong AM, Horan KA, Sriratana A, Bailey CG, Collyer LJ, Nandurkar HH, Shisheva A, Layton MJ, Rasko JE, Rowe T et al. 2006 Phosphatidylinositol 3-phosphate [PtdIns3P] is generated at the plasma membrane by an inositol polyphosphate 5-phosphatase: endogenous PtdIns3P can promote GLUT4 translocation to the plasma membrane. Molecular and Cellular Biology 26 6065-6081. (doi:10.1128/MCB.00203-06)

Kutateladze TG 2010 Translation of the phosphoinositide code by PI effectors. Nature Chemical Biology 6 507-513. (doi:10.1038/ nchembio.390)

Lazar DF \& Saltiel AR 2006 Lipid phosphatases as drug discovery targets for type 2 diabetes. Nature Reviews. Drug Discovery 5 333-342. (doi:10.1038/ nrd2007)

Manning BD \& Cantley LC 2007 AKT/PKB signaling: navigating downstream. Cell 129 1261-1274. (doi:10.1016/j.cell.2007.06.009)

Martin SS, Haruta T, Morris AJ, Klippel A, Williams LT \& Olefsky JM 1996 Activated phosphatidylinositol 3-kinase is sufficient to mediate actin rearrangement and GLUT4 translocation in 3T3-L1 adipocytes. Journal of Biological Chemistry 271 17605-17608. (doi:10.1074/jbc.271. 30.17605)

McPherson PS, Garcia EP, Slepnev VI, David C, Zhang X, Grabs D, Sossin WS, Bauerfeind R, Nemoto Y \& De Camilli P 1996 A presynaptic inositol-5-phosphatase. Nature 379 353-357. (doi:10.1038/379353a0)

Muraille E, Pesesse X, Kuntz C \& Erneux C 1999 Distribution of the src-homology-2-domain-containing inositol 5-phosphatase SHIP-2 in both non-haemopoietic and haemopoietic cells and possible 
involvement of SHIP-2 in negative signalling of B-cells. Biochemical Journal 342 697-705. (doi:10.1042/0264-6021:3420697)

Ooms LM, Horan KA, Rahman P, Seaton G, Gurung R, Kethesparan DS \& Mitchell CA 2009 The role of the inositol polyphosphate 5-phosphatases in cellular function and human disease. Biochemical Journal 419 29-49. (doi:10.1042/BJ20081673)

Pesesse X, Deleu S, De Smedt F, Drayer L \& Erneux C 1997 Identification of a second $\mathrm{SH} 2$-domain-containing protein closely related to the phosphatidylinositol polyphosphate 5-phosphatase SHIP. Biochemical and Biophysical Research Communications 239 697-700. (doi:10.1006/ bbrc.1997.7538)

Picardi PK, Calegari VC, Prada Pde O, Moraes JC, Araujo E, Marcondes MC, Ueno M, Carvalheira JB, Velloso LA \& Saad MJ 2008 Reduction of hypothalamic protein tyrosine phosphatase improves insulin and leptin resistance in diet-induced obese rats. Endocrinology 149 3870-3880. (doi:10.1210/en.2007-1506)

Plum L, Ma X, Hampel B, Balthasar N, Coppari R, Munzberg H, Shanabrough M, Burdakov D, Rother E, Janoschek R et al. 2006 Enhanced PIP3 signaling in POMC neurons causes KATP channel activation and leads to diet-sensitive obesity. Journal of Clinical Investigation 116 1886-1901. (doi:10.1172/JCI27123)

Quon MJ, Chen H, Ing BL, Liu ML, Zarnowski MJ, Yonezawa K, Kasuga M, Cushman SW \& Taylor SI 1995 Roles of 1-phosphatidylinositol 3-kinase and ras in regulating translocation of GLUT4 in transfected rat adipose cells. Molecular and Cellular Biology 15 5403-5411.

Sasaoka T, Hori H, Wada T, Ishiki M, Haruta T, Ishihara H \& Kobayashi M 2001 SH2-containing inositol phosphatase 2 negatively regulates insulin-induced glycogen synthesis in L6 myotubes. Diabetologia $\mathbf{4 4}$ 1258-1267. (doi:10.1007/s001250100645)

Sleeman MW, Wortley KE, Lai KM, Gowen LC, Kintner J, Kline WO, Garcia K, Stitt TN, Yancopoulos GD, Wiegand SJ et al. 2005 Absence of the lipid phosphatase SHIP2 confers resistance to dietary obesity. Nature Medicine 11 199-205. (doi:10.1038/nm1178)

Taniguchi CM, Emanuelli B \& Kahn CR 2006 Critical nodes in signalling pathways: insights into insulin action. Nature Reviews. Molecular Cell Biology 7 85-96. (doi:10.1038/nrm1837)

Ueki K, Fruman DA, Brachmann SM, Tseng YH, Cantley LC \& Kahn CR 2002 Molecular balance between the regulatory and catalytic subunits of phosphoinositide 3-kinase regulates cell signaling and survival. Molecular and Cellular Biology 22 965-977. (doi:10.1128/МСB.22.3. 965-977.2002)

Virkamaki A, Ueki K \& Kahn CR 1999 Protein-protein interaction in insulin signaling and the molecular mechanisms of insulin resistance. Journal of Clinical Investigation 103 931-943. (doi:10.1172/ JCI6609)

Wada T, Sasaoka T, Funaki M, Hori H, Murakami S, Ishiki M, Haruta T, Asano T, Ogawa W, Ishihara $\mathrm{H}$ et al. 2001 Overexpression of SH2-containing inositol phosphatase 2 results in negative regulation of insulin-induced metabolic actions in 3T3-L1 adipocytes via its $5^{\prime}$-phosphatase catalytic activity. Molecular and Cellular Biology 21 1633-1646. (doi:10.1128/MCB.21.5.1633-1646.2001)

Yin Y \& Shen WH 2008 PTEN: a new guardian of the genome. Oncogene 27 5443-5453. (doi:10.1038/onc.2008.241)

Received in final form 21 January 2013

Accepted 24 January 2013

Accepted Preprint published online 24 January 2013
(C) 2013 Society for Endocrinology Printed in Great Britain 